\title{
Percutaneous biliary drainage with emphasis on hilar lesions
}

\author{
R GRAY, MD, CM, FRCPC,
}

\begin{abstract}
The mortality rates of surgery and percutaneous transhepatic biliary drainage (PTHBD) are comparable. Long term studies show that delayed complications occur in the majority of cases of PTHBD and survival is not improved compared to surgery. The many recent advances in endoscopic and percutaneous drainage techniques and the recognition that the patient is best served by a noncompetitive multidisciplinary approach will ensure that virtually every patient obtains the most satisfactory drainage possible with a minimum of risk and discomfort. Endoscopic drainage should be the first therapeutic option, with radiologic assistance in the 15 to $25 \%$ where endoscopic drainage fails or is incomplete. Can J Gastroenterol 1990;4(9):579-587
\end{abstract}

Key Words: Bile ducts, Interventional radiology, Stenosis or obstruction

\section{Le drainage percutané transhépatique des voies biliaires et les lésions hilaires}

RESUME: Les taux de mortalité des interventions chirurgicales et du drainage percutané transhépatique des voies bilaires (DPTVB) sont comparables. Des études à long terme démontrent que des complications à retardement surviennent dans la majorité des cas et que le DPTVB n'améliore pas la survie par rapport à la chirurgie. Les nombreux progrès récemments réalisés dans le domaine des techniques de drainage percutané et endoscopie, et la reconnaissance du fait que le patient est mieux servi par une approche multidisciplinaire non concurrentielle, garantira virtuellement à chaque patient le drainage le plus satisfaisant possible avec le minimum de risque et de malaise. Le drainage endoscopique devrait constituer la première option thérapeutique, et s'effectuer sous assistance radiologique dans les 15 à $25 \%$ des cas où le drainage endoscopique non guidé échoue ou est incomplet.

$P_{b}$
ERCuTANEOUS TRANSHEPATIC biliary drainage (PTHBD) was developed more than 15 years ago (1). The early reports of this technique were very enthusiastic, with particular emphasis on the marked decrease in morbidity and mortality relative to surgical drainage.
However, many of these early papers compared the 'surgical' mortality of surgical procedures with the procedural mortality of PTHBD - 20 to $30 \%$ and 0 to $4 \%$, respectively $(2,3)$. With time it became clear that if the same criterion - 30 day mortality - used by surgeons was applied to both techniques, then
Associate Professor of Radiology, University of Toronto, Toronto, Ontario

Correspondence and reprints: Dr R Gray, Department of Radiology, The Wellesley Hospital, 160 Wellesley Street East, Toronto, Ontario M4Y 1J3. Telephone (416) 926-7684 the mortality rates of surgery and PTHBD were comparable (4). With time, the low complication rates reported in early series were seen in part to be the result of short follow-up periods. Longer term studies showed that delayed complications occurred in the majority of cases and survival was not improved compared to surgery (5).

The long term survival of patients with malignant obstruction was shown to be dependent on the condition of the patient, not on the mode of drainage (6). PTHBD remained a part of the medical armamentarium because it was a simpler and more cost effective way of treating patients compared to surgery, and patients had shorter hospital stays.

When endoscopic drainage became available $(7,8)$, several comparative studies showed decreased morbidity compared to PTHBD $(9-11)$. The decreased morbidity was due in part to the avoidance of liver and vascular damage by endoscopic drainage, and partly to obviation of liver puncture. Endoscopic drainage was also less painful to perform and did not require an external tube. PTHBD then experienced a decline in popularity, partly for the above reasons and partly because referrals from gastroenterologists dried up.

A resurgence of PTHBD has occurred in the past few years (12) as it has become clear that not all biliary obstructions can be handled by endoscopists alone. Radiologic support is important in patients with obstruction of the upper gastrointestinal tract, prior 

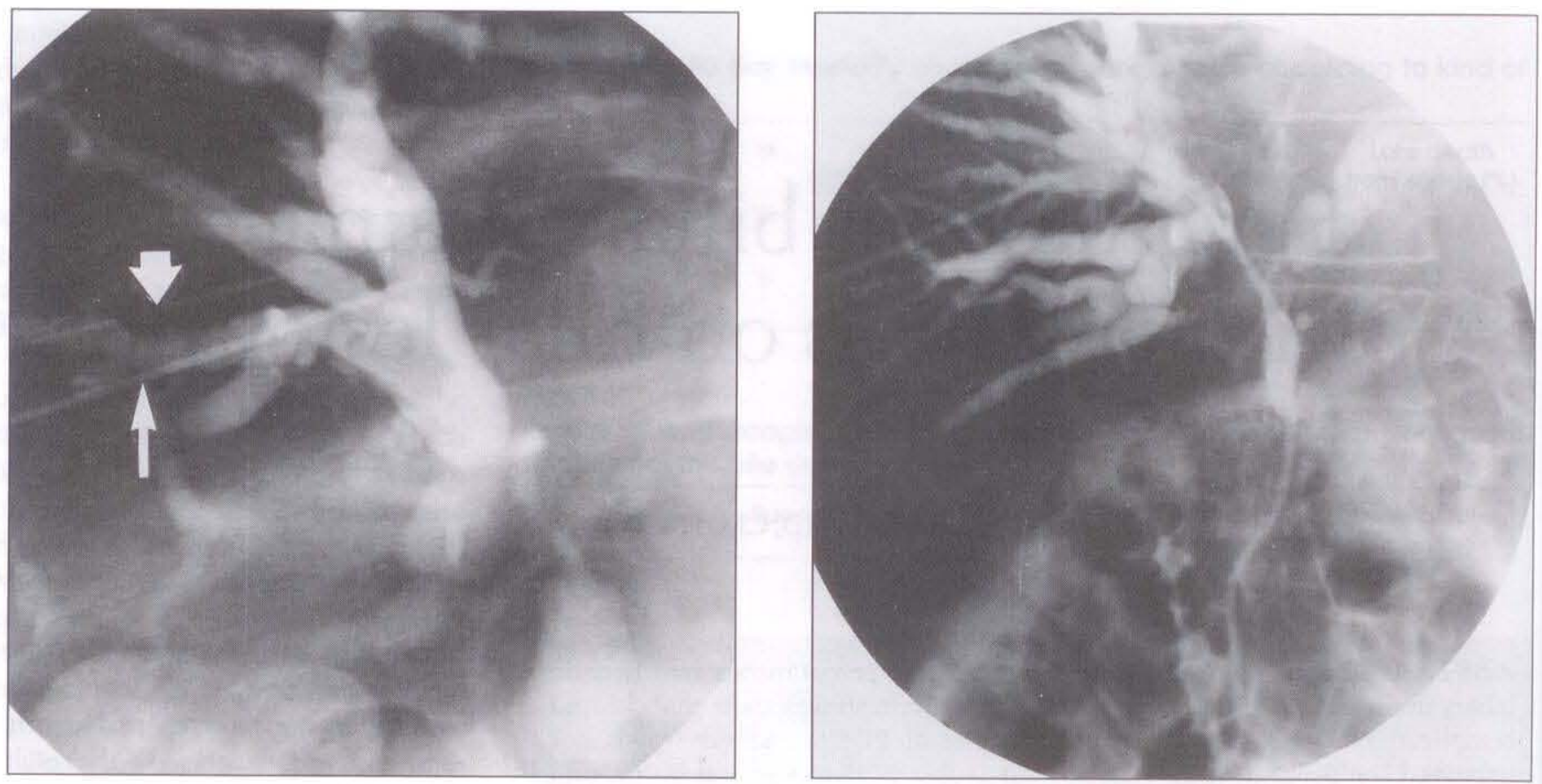

Figure 1) Radiologic right duct drainage. Left Transhepatic cholangiography demonstrates a Klatskin tumour. The 22 gauge needle (arrowhead) was used to opacify the ducts. An 18 gauge needle (arrow) has been placed into a right hepatic duct branch with a good angle of approach to the stricture. Right A single right internal percutaneous transhepatic biliary drainage catheter provided adequate drainage. Despite the high grade obstruction of the left duct system, a left-sided catheter was not required. Note the longer unbranched length of left duct, which makes left drainage preferable in many patients. In this patient the right duct obstruction extends up to the first division point

surgery (especially Roux-en-Y loops and Billroth II anastomoses) and endoscopic failures. Cremer (13) notes that radiological help is required in $25 \%$ of hilar lesions.

'Turf' battles have been overcome in part by the introduction of combined radiologic-endoscopic procedures $(14,15)$. Furthermore, a host of new applications has been developed.

Over the past 15 years there have been many technical developments which have improved the ease, safety and success rates of these procedures. Among the most important are the heavy duty guidewires developed by Lunderquist (16) and improved by Amplatz, which facilitate dilation of the track and catheter insertion. A variety of wires has also been developed to aid in bypassing tight and tortuous strictures such as the Lunderquist-Ring torque control wire, the variable core wire and the polymer coated 'glide' wire. Drainage catheters are now made of softer, more comfortable materials, have better retention devices and a greater resistance to encrustation. A wide variety of percutaneously place. able endoprostheses has also been developed for increased ease of placement and longer functioning life.

\section{INDICATIONS AND APPLICATIONS}

Currently in the author's institution and many others, the main indication for PTHBD is obstructed biliary tree following failure of endoscopic drainage. In many other centres where endoscopic drainage is not available, PTHBD remains the first-line approach to the obstructed biliary tree.

Other indications include: extraction (17,18), displacement (19-22), dissolution (23-25) and lithotripsy (26) of bile duct stones; dilation of bile duct strictures (27-29); management of biliary sepsis arising either de novo or as a complication of a prior drainage procedure (30-32); sampling of bile for cytology $(33,34)$ or bacteriology; decompression of biliary leak or fistula (35); access to bile ducts for placement of local radiotherapy source (36); biopsy of obstructing lesions (37); papillotomy (38) or electroincision of strictures (39); access to the biliary tree for laser coagulation of bleeding (40); placement of feeding tubes into the duodenum or jejunum $(41,42)$; drainage of 'afferent loop syndrome' (43); access to ducts for excision of neoplasm $(44,45)$; biliary manometry (46); and management of Caroli's disease (47).

Some early studies suggested that routine preoperative drainage of surgical candidates with hyperbilirubinemia was a helpful procedure (48), but other studies have not borne this out (49), and preoperative drainage has fallen out of favour.

\section{TECHNIQUE}

PTHBD is painful, so standard PTHBD technique begins with sedation of the patient and good analgesia. Most patients are given intravenous narcotics, usually morphine or fentanyl, with the dose titrated to the patient's pain level.

A variety of other methods of pain control are applied as required. Some authors add intercostal nerve blocks to the usual extensive infiltration of local anesthetic in order to control somatic 

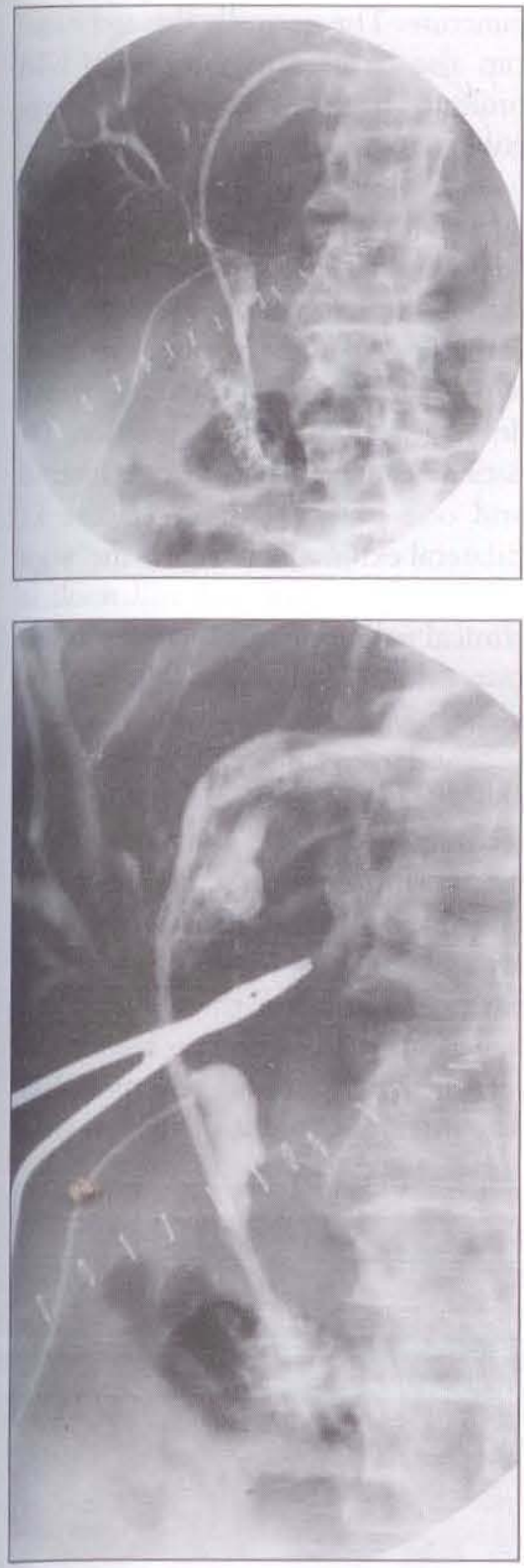

Figure 2) Radiologic left duct drainage. Top The tumour extends into the origins of several segmental branches on the right in this patient with cholangiocarcinoma. A left internal drain was therefore placed. Bottom Subsequently a $12 \mathrm{~F}$ endoprothesis was placed through the transhepatic track. The percutaneous transhepatic bilary drainage catheter was later withdrawn.

or abdominal wall pain (50). Celiac ganglion blockade can reduce deep 'visceral' pain (51), and some authors use it routinely. Intrapleural block can reduce both somatic and visceral pain (52). It can also be performed during PTHBD if necessary (53). Rarely, epidural or general anesthesia may be required for patients to tolerate the procedure (50).
Some radiologists use routine antibiotic prophylaxis (54); others do not.

A fine needle cholangiogram is usually performed as the initial step to outline the anatomy and select an appropriate duct $(55,56)$. This part of the procedure may be done blindly using only abdominal wall and radiologic landmarks, or it may be guided by ultrasound (57). Care must be taken to inject the least amount of contrast necessary to plan the procedure. Undue elevation of intraductal pressure is thought to contribute to the incidence of sepsis (58). Carbon dioxide may be introduced to show the left duct system, since it will rise anteriorly with the patient supine. Because there is a risk of sepsis with injection, some radiologists forego the diagnostic and 'mapping' cholangiogram and go directly to drainage. A variety of instruments have been developed for 'single stick' drainage (59).

After the cholangiogram has shown the duct system, an appropriate duct is selected for puncture (Figure 1). The puncture site is just anterior to the mid axillary line below the 10 th rib to avoid lung and pleural space. A lower puncture site should be chosen if this will result in an appropriate, preferably straight or downward approach to the chosen duct, or if the lung clearly comes below the 10th rib. The author performs lateral fluoroscopy in order to ensure a horizontal approach to the chosen duct. Once the duct is punctured, a guidewire is introduced as far as possible to secure the track, which is then dilated and a torquable catheter is introduced. The catheter and wire are then manipulated beyond the obstruction into the duodenum. When the guiding catheter is removed, the drainage catheter is placed over the in situ guidewire (Figure 1).

If purulent bile is encountered or if the patient is septic, no attempt is made to bypass the obstruction. An external drain is left in place until all septic symptoms and signs subside. An internal drain can then be placed at leisure.

Some radiologists now prefer to drain the biliary tree through the left hepatic duct $(60,61)$ (Figure 2). The volume of the left lobe is sufficient to maintain liver function in patients with both ducts obstructed by hilar lesions. If the obstruction is below the hilum then the entire biliary tree can be drained. Several advantages are realized by a leftsided approach. The lung, pleura and diaphragm are all avoided, and therefore chest complications do not occur (62). Pleuritic and shoulder tip pain and splinting are also almost eliminated. Reduced overall complications have also been documented (61). In the author's experience patients have much less long term discomfort, possibly because the catheter is less disturbed by respiratory movement. A further advantage is that the left hepatic duct has a longer length of unbranched duct above the confluence than does the right. In practical terms this means that a circumferentially expanding lesion takes longer to obstruct secondary branches on the left than on the right. Left-sided catheters should therefore have a longer useful life before progressive segmental isolation occurs. Ultrasound localization of the ducts has been particularly useful on the left $(57,60)$. The main disadvantage of left duct drainage is the increased radiation dose to the hands of the radiologist (60).

\section{SPECIAL CONSIDERATIONS IN HILAR LESIONS}

The basic principle guiding interventional radiologic procedures is to get the most effective result with the least risk and discomfort to the patient. Best of all is if a good result can be obtained by single or double endoprosthesis placement via a transpapillary route. If only one side can be entered from below, the radiologist can drain the undrained lobe if necessary (Figure 3 ). In the event of complete failure of endoscopic drainage, it is best if effective palliation of symptoms can be achieved with either a single left or right drain as described above.

Some authors (63) recommend draining both duct systems routinely in patients with hilar obstruction to prevent the development of cholangitis in the undrained lobe. The author does this routinely in patients in whom prior endoscopic drainage has been attempted. However, when both ducts 

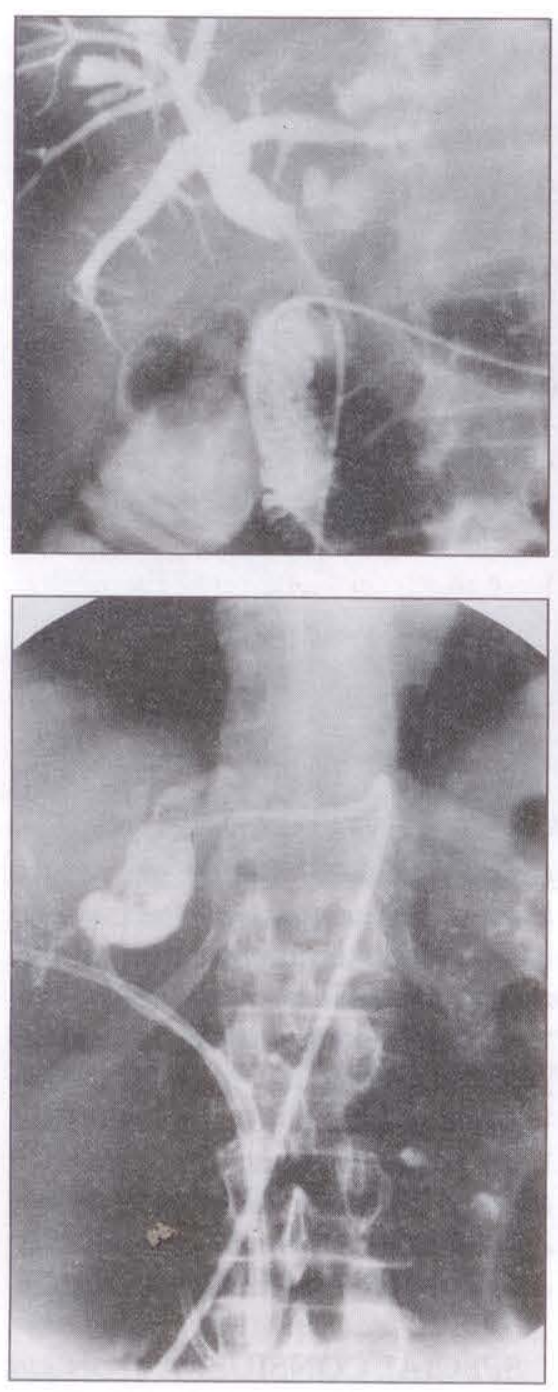

are drained, the risks are additive. If the biliary system has not been contaminated by the endoscopist, generally only a single (left) PTHBD catheter is placed. Should the patient show any evidence of sepsis unresponsive to conservative therapy or not achieve adequate palliation of symptoms, the author proceeds to decompression of the undrained lobe (Figure 4).

A variety of ingenious procedures have been developed to reduce the number of PTHBD catheters and/or percutaneous punctures. In early cases the author placed internal right and external left drains through the same right lateral puncture. Druy and Melville (64) used a similar technique but linked the tubes via an external connector so that the left duct drainage passed into the right internal drain and therefore also drained internally. By later conver-

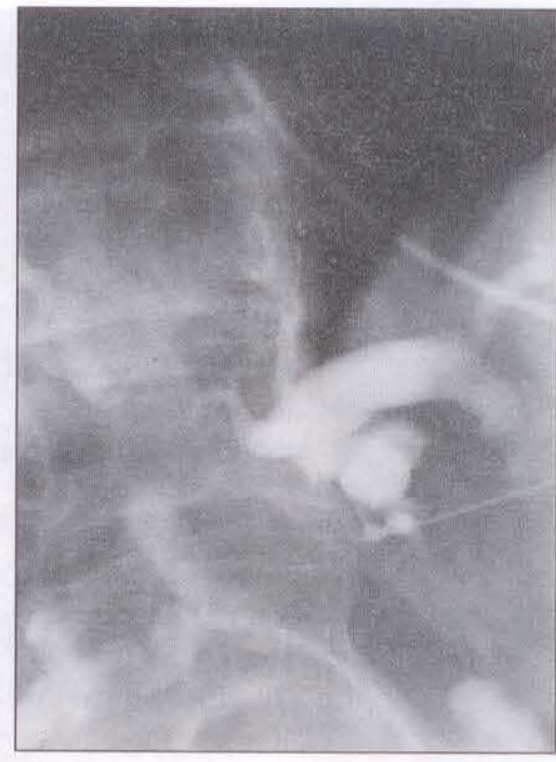

Figure 3) Radiologic assistance. Top left Endoscopic drainage was established via a nasobiliary catheter in the right hepatic duct. The left system could not be catheterized and the patient became septic. Above Subcostal percutaneous transhepatic cholangiography in inferior branch of left hepatic duct. Left Final configuration. Right endoprosthesis and left internal percutaneous transhepatic biliary drainage

sion of the right drain to an endoprosthesis and capping of the left, complete internal drainage was achieved, with only a single (left) catheter remaining external.

Uflacker (65) modified this 'crossover' technique further with placement of two internal stents (Figure 5). His group also used a similar technique (65) in which the 'crossover' endoprosthesis did not pass from right to left via the duct system but through a transparenchymal tract (Figure 6). Even T tubes have been used to drain both ducts from one puncture (66). Burke and McLean (67) modified a Cope loop gastrostomy catheter. The catheter could be placed so that some holes were in both right and left ducts and some in the jejunum, allowing effective internal drainage of anastomotic choledochojejunal stricture via a single right puncture. Theoretically this technique can also be used in the case of hilar tumours if the duct below is large enough to accept the loop.

If single puncture drainage of both ducts fails or is not feasible, it may still be possible to place an internal drainage catheter from one side, and a crossover catheter or prosthesis from the other, which will still allow bilateral internal drainage. As a fallback position, the patient can be left with one internal and one external drain (Figure 4). Bilateral external drainage is the 'worst case' scenario, but will still result in clinical palliation, albeit at the cost of two external tubes and bile replace. ment therapy.

The large number of options avail. able and the ingenuity of some of these techniques can lead to technically effective drainage in the majority of obstructed patients. However, it must always be kept in mind that most patients requiring these techniques have limited lifespans no matter how technically successful the procedure. The interventionalist should be careful

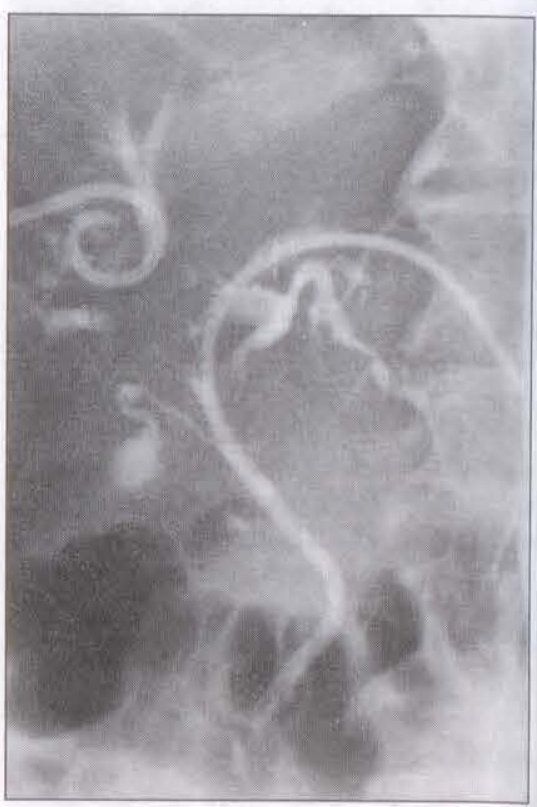

Figure 4) Bilateral radiologic drainage. Frank pus was aspirated from the left biliary system during placement of the left percutaneous trans. hepatic biliary drainage catheter in this patient with a hilar cholangiocarcinoma. A right catheter was therefore placed as well. The right duct stricture could not be negotiated. The final configuration is an external right drain and an internal left one 

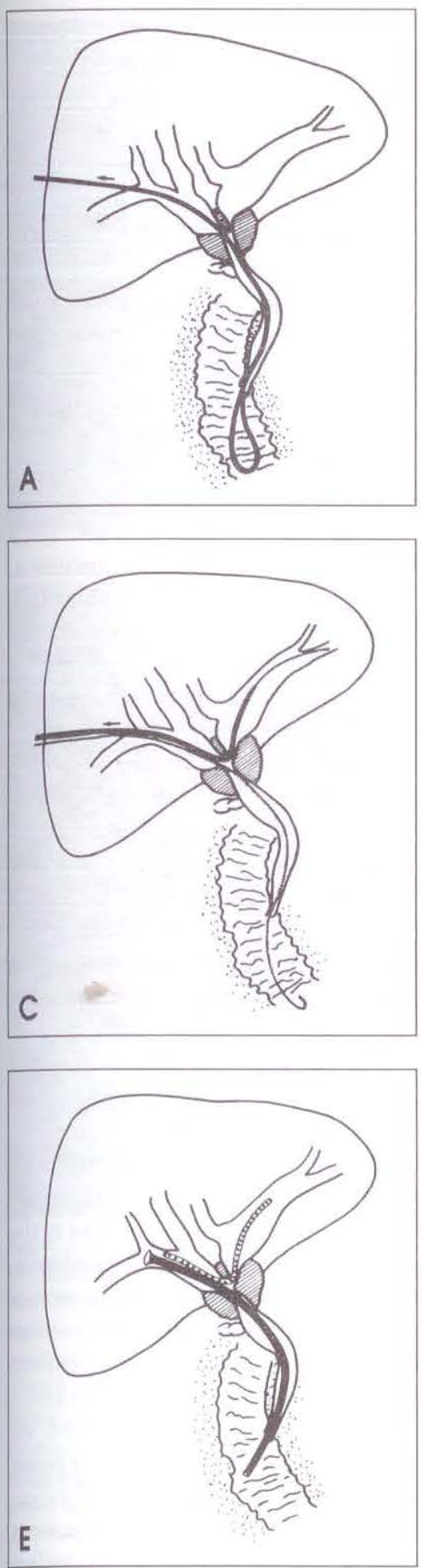

not to let the demonstration of his technical virtuosity supercede what is best for the patient. Each drainage procedure is done at the cost of risk and discomfort to the patient and financial cost to the patient or health care system. McLean (68) set a limit of three punctures per patient. In the author's
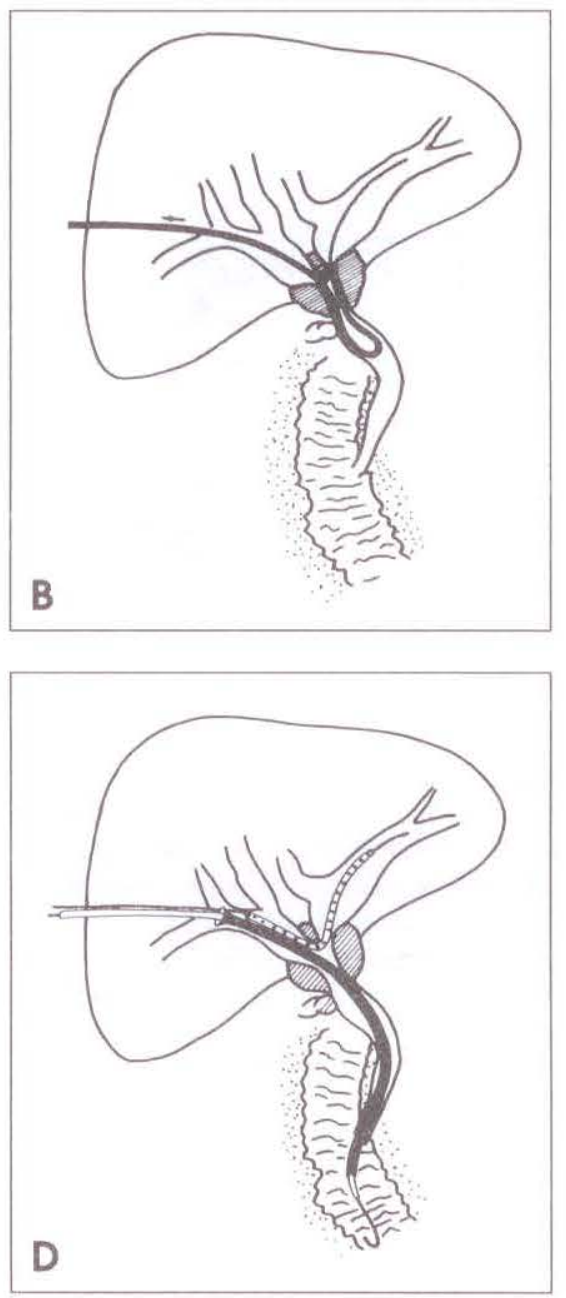

Figure 5) Crossover technique. A A Simmons catheter with a recurved loop is formed in the duodenum, after placement from a right lateral approach. B By retracting the catheter, the recurved loop can be passed into the left hepatic duct. C A guidewire is placed in the left duct through the catheter. A second guidewire can be introduced through a coaxial sheath and manipulated into the duodenum. D Endoprostheses (or catheters) can be placed over both wires. E Final configuration. The left system drains across to the right and both drain via the right endoprosthesis or catheter into the gut. (Reprinted with permission from Uflacker $R$, et al. Gastrointest Radiol 1989; 14:137-42)

early cases as many as five separate segmental drainages were performed, but the author is currently more restrictive even than McLean, and no longer performs more than two primary drainage procedures per patient. The great advantage of PTHBD over endoscopic drainage is the very high success rate (greater than 98\%) in establishing drainage.

\section{COMPLICATIONS OF PERCUTANEOUS DRAINAGE}

The major complications of percutaneous drainage, whether by internal or external catheter or by endoprosthesis, are related to the creation of a track from the skin to the bile duct. This track, of necessity, passes through the liver and peritoneal space. It may also pass through the hemidiaphragm and pleural space if a right lateral approach is used. Bleeding, a major cause of mortality and morbidity, is undoubtedly the result of laceration of blood vessels and/or liver parenchyma. Such lesions occur in up to $33 \%$ of PTHBD patients (69). Hemobilia is the most common complication in some series and may be fatal (70). Lesser degrees of hemorrhage may require transfusion or embolotherapy to control bleeding (71). The types of lesions requiring therapeutic intervention included hepatic artery aneurysms, hepatic artery-portal vein fistulae and venous varices (71).

Immediate sepsis is likely the result of transient biliary venous fistulae created during the procedure (58). Delayed infection, ie, cholangitis, occurs in up to $47 \%$ (72). In Carrasco's series $(58,72)$ cholangitis was more common in patients with internally versus externally draining catheters. In the present author's experience of over 300 cases, cholangitis is almost invariably the result of poor drainage, and if patients live long enough, all catheters will become occluded or function poorly. For this reason all PTHBD catheters are routinely exchanged at 60 to 90 day intervals. Using this routine the author has almost been able to eliminate cholangitis in patients with indwelling PTHBD catheters. Cholangitis can also develop with multiple strictures and undrained segments (73).

Bile leakage is another complication of the transhepatic track. It may come about as a result of poor technique, catheter obstruction by clots or debris or catheter dislodgement (72). Bile peritonitis can occur if the catheter dislodges before a fibrous track to the skin 

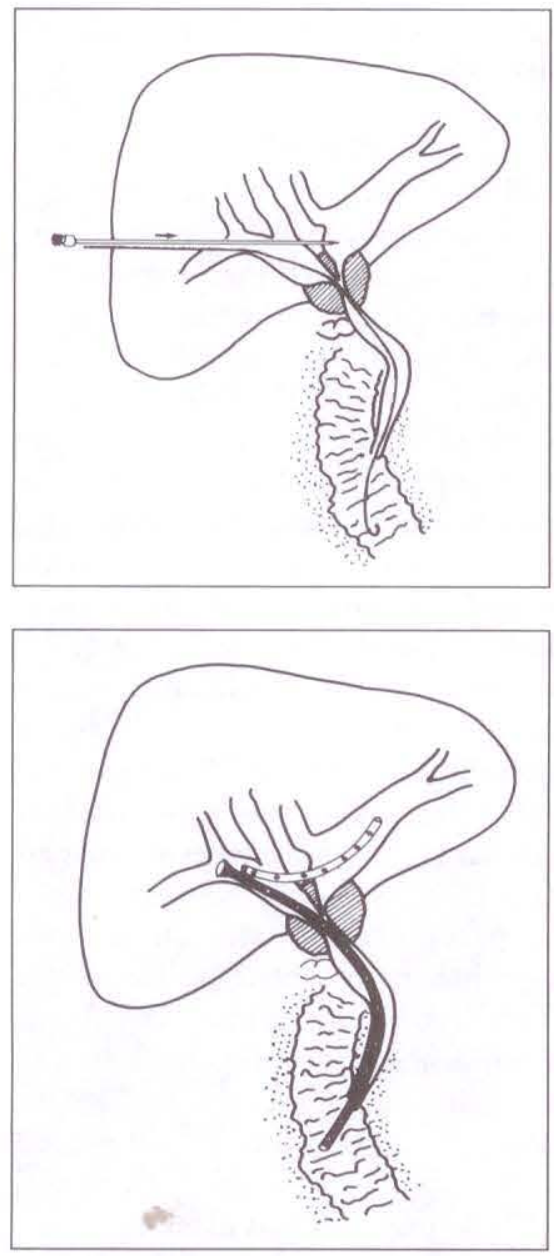

forms, and can be fatal particularly when the bile is infected. Bile leakage along the track around an indwelling catheter can generally be controlled by placement of a larger catheter. If the catheter dislodges after a good biliarycutaneous track has formed, replacing the catheter along the pre-existing route is generally simple $(74,75)$. If a track has not formed, then a new biliary drainage procedure may be required. Laparotomy may also be needed if sufficient bile leakage into the peritoneal space has occurred.

Other complications directly related to track placement are pneumothorax, pleural effusion, empyema (76), hemothorax, biliary-pleural fistula and malignant pleural effusion (77). As previously mentioned, pleural and pulmonary complications are obviated by draining the ducts from an anterior (left duct) approach.

Tumour can grow along the catheter track and spread to skin (78), peritoneal

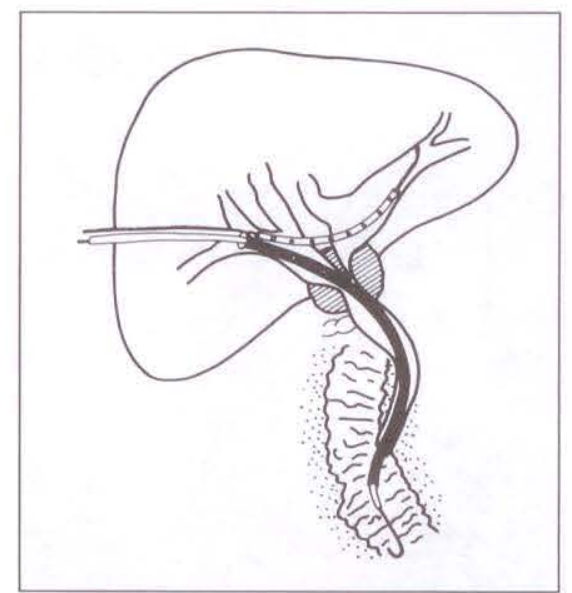

Figure 6) Alternate crossover technique when the orifice of the left system cannot be cannulated. Top left Through the same right lateral approach, a guidewire is passed through one needle into the duodenum. A second needle is passed transparenchymally from the right hepatic duct to the left, through which a second guidewire is placed. Above Endoprostheses are passed over both guidewires. Left Final configuration. There is left to right flow of bile through the crossover drain. Both systems drain into the gut via the right drain. (Reprinted with permission from Uflacker $R$, et al. Gastrointest Radiol 1989;14:137-42)

space (79) and pleural space (77). Long term catheters can also be complicated by erosion of ribs (80).

Some skin and abdominal wall discomfort is common and may in some patients require nerve block or local anesthesia for relief (81).

Other complications are the results of technical problems, eg, duodenal perforation (82) or knotted catheters (83). Still others are of uncertain etiology, such as acute cholecystitis (84).

Yee and Ho (85) compared complication rates in patients with benign and malignant obstructions and found substantially fewer major complications ( 2 versus $7 \%$ ) and deaths ( 0 versus $2 \%$ ) in the benign group. Presumably these differences reflect the poor condition and more advanced age of the malignancy group. The death rate in the multiple series reviewed by Yee ranged from 0 to $6 \%$. Deaths in most series resulted from hemorrhage, sepsis or bile peritonitis.

\section{ENDOPROSTHESES VERSUS CATHETER DRAINAGE}

Many radiologists prefer to place endoprostheses rather than PTHBD catheters, and in the preceding discussion the terms 'stent' or 'endoprosthesis' can serve in place of 'PTHBD catheter' or 'drain.'

Endoprostheses have proven effective when placed by endoscopist $(86,87)$ or radiologist $(88,89)$, although Speer $(90)$ has shown mortality to be less with endoscopic drainage stents than catheters. It is not the author's intention to debate the relative merits of PTHBD and endoprostheses. Many factors enter into such a discussion, among them the technical skills of the endoscopist and radiologist, the psychological state, preferences and life expectancy of the patient, where the patient lives and how he will be monitored, and the number, type and sites of the obstructing lesions $(91,92)$.

Radiologists can place stents in virtually any duct system in which they have obtained internal drainage. If the stent cannot be placed in the usual antegrade manner, then a radiological method of transpapillary placement has been developed which is analogous to endoscopic placement, but does not require an endoscope (93). A wire placed percutaneously is retrieved from the duodenum by a perorally placed basket which is manipulated into position under fluoroscopic guidance. One end of the wire is then pulled up and the endopros. thesis attached. By a combination of pushing and pulling the endoprosthesis is drawn back into the gut and then into position across the duct obstruction.

Alternatively a wire placed via PTHBD catheter is retrieved by a basket under endoscopic guidance and the endoprosthesis placed in a similar manner $(14,94)$. A third method, which is often used in the author's department, is for the endoscopist to place a wire alongside the PTHBD catheter (Figure 7). The wire will often cross the previously impassable stricture, presumably because the catheter has either straightened the track or has slightly eroded the obstructing lesion as a result of continuous movement with respiration. The percutaneous track can be 

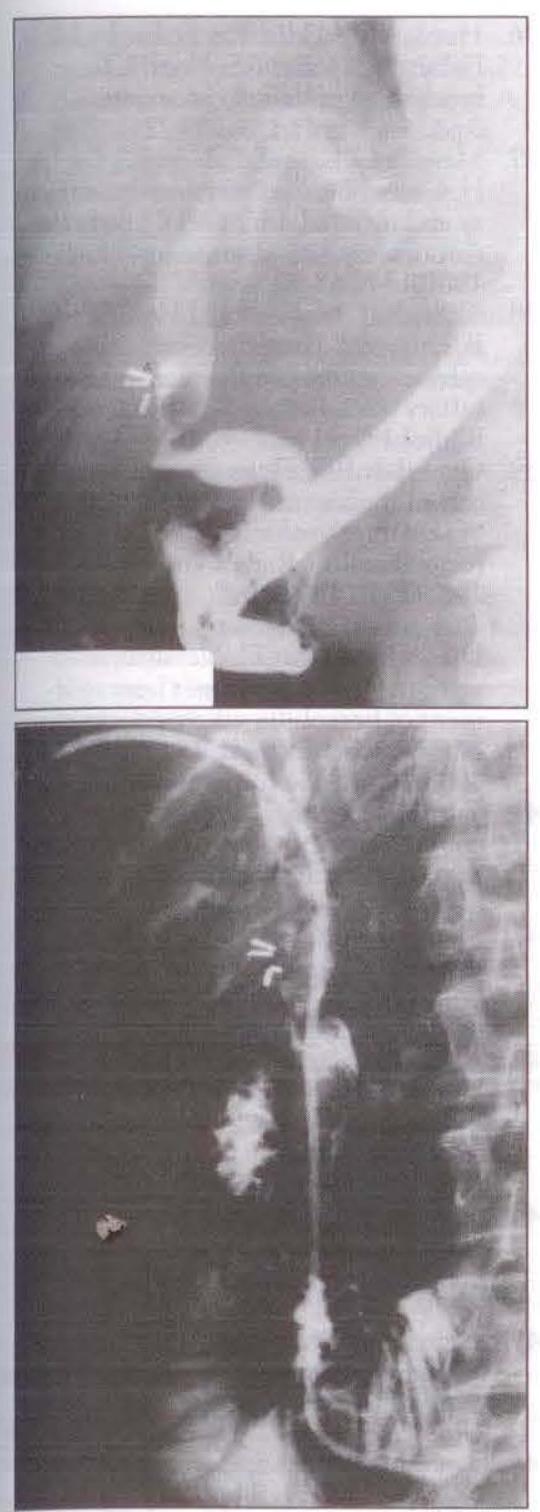

Figure 7) Endoscopic retrograde cholangiopancreatography. Top Attempts to pass a guidewire were unsuccessful. The wire kept passing out the T-tube track (arrowhead) and would not negotiate the $90^{\circ}$ bend, the upper end of which was blocked by a stone. Bottom Following percutaneous transhepatic biliary drainage, the bend in the duct has been straightened by the catheter, and the stone pushed below the area of stenosis. The endoscopist was able to pass a guidewire and endoprosthesis alongside the catheter without difficulty

plugged with gelfoam or coils when the PTHBD catheter is removed.

Placing stents by any of these retrograde methods has the advantage of allowing a large stent to be positioned without creation of a large hole in the liver, a major cause of mortality with percutaneous stent placement (91).
The pain associated with dilation of the liver track is eliminated and, theoretically at least, there is a decreased risk of bleeding. The author prefers therefore to let the endoscopists place stents rather than place them radiologically.

Another reason to place endoprostheses by one of these methods is to ensure that endoscopic replacement will be possible if the prosthesis occludes.

While occluded endoprostheses can be exchanged radiologically (95), the author elects not to place them in patients where endoscopic exchange is not feasible, because replacement would require an additional PTHBD procedure with all the attendant risks. An endoprosthesis which is not endoscopically changeable is placed only if the patient has a very short life expectancy and will likely die before occlusion of the endoprosthesis occurs. In summary, if a stent cannot be placed endoscopically, it is generally preferable to leave a PTHBD catheter in place. Exchange of an occluded or displaced PTHBD catheter is a quick painless outpatient procedure.

\section{RECENT DEVELOPMENTS AND FUTURE DIRECTIONS}

Large diameter metal stents (up to 30 French) have been developed (96). These stents can be placed through 8 to $10 \mathrm{~F}$ delivery systems. The theory behind them is that larger diameter stents will be less likely to occlude than the 10 to $14 \mathrm{~F}$ stents in general use today.

Preliminary reports from Britain suggest that this hope may not be realized. Gillams (97) reported that recurrent jaundice occurred in $42 \%$ of patients treated with "Wallstents." Tumour growth through the interstices of the metal mesh or beyond the ends of the stent was among the reasons.

A variation which may prevent tumour growth between the wires of the stent involves a polymer coating which in effect makes the walls of the stent one solid piece without holes. This type of stent is not self-expanding and requires balloon expansion, accomplished by a catheter-mounted balloon similar to that used for angioplasty (98). Tumour growth through or above the stent is clearly not a problem in benign diseases, and the expected beneficial result of larger stents has been realized in a small group of patients with nonmalignant obstructions (99).

\section{CONCLUSIONS}

In general, the author places endoprostheses endoscopically as a firstline approach. Any of the methods described above may be used to place a stent endoscopically after PTHBD if the original endoscopic drainage fails. Rarely, a stent must be placed radiologically in a patient in whom, for technical reasons (eg, esophageal obstruction), these methods cannot be used. If the stent cannot be placed endoscopically, it cannot be changed endoscopically either. Occlusion of the stent will then require another PTHBD with all the attendant risks. Therefore, in this special circumstance, radiological stent placement will be performed if and only if the patient's life expectancy is less than the expected stent life. If the patient is likely to have a longer survival, then the author leaves him with a PTHBD catheter, which can be readily and safely exchanged on an outpatient basis. Such catheters are routinely changed at 90 day intervals.

The many recent advances in endoscopic and percutaneous drainage techniques, and the recognition that the patient is best served by a noncompetitive multidisciplinary approach (15) will ensure that virtually every patient obtains the most satisfactory drainage possible with a minimum of risk and discomfort. Endoscopic drainage should be the first therapeutic option, with radiologic assistance in the 15 to $25 \%$ where endoscopic drainage fails or is incomplete.

\section{REFERENCES}

1. Molnar W, Stockum AE. Relief of obstructive jaundice through percutaneous transhepatic catheter - A new therapeutic method. Am J Radiol 1974;122:356-66.

2. Harbin HP, Ferrucci JT. Nonoperative management of malignant biliary obstruction: A radiologic alternative. Am J Radiol 1980;135:103-7.

3. Berquist TH, May GR, Johnson CM, Adson MA, Thistle JL. Percutaneous biliary decompression: Internal and external drainage in 50 patients. Am J Radiol 1981;136:901-6. 
4. Clark RA, Mitchell SE, Colley DP, Alexander E. Percutaneous catheter biliary decompression. Am J Radiol 1981;137:503-9.

5. Mueller PR, van Sonnenberg E, Ferrucci JT. Percutaneous biliary drainage: Technical and catheter related problems in 200 procedures. Am J Radiol 1982;138:17-23

6. Bonnel D, Ferrucci JT, Mueller PR, Lacaine F, Peterson HF. Surgical and radiological decompression in malignant biliary obstruction: A retrospective study using multivariate risk factor analysis. Radiology 1984;152:347-51.

7. Soehendra N, Reijnders-Frederix V. Palliative bile duct drainage - A new endoscopic method of introducing a transpapillary drain. Endoscopy 1980;12:8-11.

8. Huibregtse K, Haverkamp HJ, Tytgat GN. Transpapillary positioning of a large $3.2 \mathrm{~mm}$ biliary endoprosthesis. Endoscopy 1981;13:217-9.

9. St Louis EL, Gray RR, Haber G, Kortan P, Grosman H. Comparison of endoscopic and percutaneous biliary drainage. Presented at the 47th Annual Meeting of the Canadian Association of Radiologists, Vancouver, June $17-21,1984$

10. Stanley J, Gobien RP, Cunningham J, Andriole J. Biliary decompression: An institutional comparison of percutaneous and endoscopic methods. Radiology 1986;158:195-7.

11. Marks WM, Freeny PC, Ball TJ, Gannan RM. Endoscopic retrograde biliary drainage. Radiology 1984;152:357-60.

12. Mueller PR. Interventional radiology of the biliary tree: A decade of progress. Radiology 1988;168:328-40,

13. Cremer M, Deviere J. Bifurcation tumors: Is endoscopic drainage sufficient? Presentation at the Fourth International Conference on Therapeutic Endoscopy, Toronto, 1989.

14. Ayela P, Ponchon T, Valette PJ, Chavaillon A, Maillet P. A combined endoscopic and radiological method for biliary drainage. Gastrointest Endosc 1988;34:42-4.

15. Chespak LW, Ring EJ, Shapiro HA, Gordon RL, Ostroff JW. Multidisciplinary approach to complex endoscopic biliary intervention. Radiology 1989;170:995-7.

16. Lunderquist $A$, Lunderquist $M$, Owman T. Guide wire for percutaneous transhepatic cholangiography. Radiology 1979;132:228.

17. Clouse ME, Stokes KR, Lee RGL, Falchuk KR. Bile duct stones: Percutaneous transhepatic removal. Radiology 1986;160:525-9.

18. Stokes KR, Falchuk KR, Clouse ME. Biliary duct stones: Update on 54 cases after percutaneous transhepatic removal. Radiology 1989;170:999. 1001.

19. Berkman WA, Bishop AF, Palagallo GL, Cashman MD. Transhepatic balloon dilatation of the distal common bile duct and ampulla of Vater for removal of calculi. Radiology 1988; 167:453-5.

20. Meranze SG, Stein EJ, Burke DR, Harty WH, McLean GK. Removal of retained common bile duct stones with angiographic occlusion balloons. Am ] Radiol 1986;146:383-5

21. Graziani L, Fabrizzi G, Manfrini E, Galeazzi R, Freddara U. Percutaneous transhepatic Oddi-sphincter dilatation for bile duct stone removal. Am J Radiol 1989:152:73-5

22. Saeed M, Newman GE, Dunnick NR. Use of angioplasty balloons in the percutaneous management of biliary cal culi: Tandem-balloon method. Am J Radiol 1987; 148:745-6.

23. Teplick SK, Haskin PH, Goldstein $\mathrm{RC}$, et al. Common bile duct stone dissolution with methyl tertiary butyl ether: Experience with three patients. Am J Radiol 1987;148:372-4.

24. Haskin PH, Teplick SK, Sammon JK, Gambescia RA, Zitomer N, Pavlides CA. Monooctinoin infusion and stone removal through the transparenchyma tract: Use in 17 patients. Am J Radiol 1987; 148:185-8.

25. Brandon JC, Teplick SK, Haskin PH, et al. Common bile duct calculi: Updated experience with dissolution with methyl tertiary butyl ether. Radiology 1988; 166:665-7.

26. Lear JL, Ring EA, Macoviak JA, Baum S. Percutaneous transhepatic electrohydrolytic lithotripsy. Radiology 1984:150:589-90.

27. Mueller PR, van Sonnenberg E, Ferrucci JT, et al. Biliary stricture dilatation: Multicentre review of clinical management in 73 patients. Radiol ogy 1986;160:17-22.

28. Moore AV, Illescas FF, Mills SR, et al. Percutaneous dilation of benign strictures. Radiology 1987;163:625-8.

29. Williams HJ, Bender CE, May GR. Benign post-operative biliary strictures: Dilatation with fluoroscopic guidance. Radiology 1987;163:629-34.

30. Nunez D, Guerra JJ, Al-Sheikh WA, Russell E, Mendez G. Percutaneous biliary drainage in acute suppurative cholangitis. Gastrointest Radiol 1986;11:85-9.

31. Lois JF, Gomes AS, Grace PA, Deutsch LS, Pitt HA. Risks of percutaneous transhepatic drainage in patient with cholangitis. Am J Radiol 1987; $148: 367-71$

32. Kadir S, Baassir A, Barth KH, Kaufman SL, Cameron JL, White RI. Percutaneous biliary drainage in the management of biliary sepsis. Am J Radiol 1982;138:25-9.

33. Harell GS, Anderson MF, Berry PF. Cytologic bile examination in the diag nosis of biliary duct neoplastic strictures. Am J Radiol 1981;137:1123-6.

34. Muro A, Mueller PR, Ferrucci IT, Taft PD. Bile cytology. A routine addition to percutaneous biliary drainage. Radiology 1983;149:846-7.

35. Kaufman SL, Kadir S, Mitchell SE, et al. Percutaneous transhepatic biliary drainage for bile leaks and fistulas. Am J Radiol 1985;144:1055-8.
36. Herskovic A, Heaston D, Engler MJ, Fisburn RI, Jones RS, Noell KT. Irradiation of biliary carcinoma. Radiology 1981;139:219-22.

37. Mendez G, Russell E, Levi JU, Koolpe $\mathrm{H}$, Cohen M. Percutaneous brush biopsy and internal drainage of biliary tree through endoprosthesis. Am J Radiol 1980;134:653-9.

38. Coburn C, Makowka L, Ho CS, Taylor B, Langer B. Percutaneous transhepatic sphincterotomy in the management of biliary tract disease. Gastrointest Radiol 1986;11:273-6.

39. Guenther RW. Transhepatic transcatheter puncture of an occluded biliary intestinal anastomosis for recanalization. Radiology 1985; 155:249-50.

40. Carpenter CM, Bowers JH, Luers PR, Dixon JA, Miller FJ. Neodymium yttrium aluminum garnet laser treatment of hemobilia via a percutaneous biliary catheter track. Radiology 1983;148:853-4.

41. Train JS, Dan SI, Mitty HA. Percutaneous transhepatic hyperalimentation for patients with biliary drainage catheters. Am J Radiol 1985;144:255-6.

42. Sibbitt RR, Palmay IL, Caplan RE, Page CP, Garcia F. Percutaneous biliary drainage with an enteric feeding tube. Radiology 1985; 157:819.

43. Lee LI, Teplick SK, Haskin PH, Sammon JK, Wolferth C, Amron G. Refractory afferent loop problems: Percutaneous transhepatic management of two cases. Radiology 1987; 165:49-50.

44. Smith TP, Rosel PW, Hunter DW, et al. Percutaneous transhepatic biliary endoscopic procedures. Gastrointest Radiol 1987;12:144-7.

45. Eschelman DJ, Birkett DH, Greenfield AJ. Laser therapy of proximal biliary neoplasms. Semin Intervent Radiol 1988;5:237-40.

46. van Sonnenberg E, Ferrucci JT, Neff CC, Mueller PR, Simeone JF, Wittenberg J. Biliary pressure: Manometric and perfusion studies at transhepatic cholangiography and percutaneous biliary drainage. Radiology 1983; 148:41-50

47. Rose SC, Kumpe DA, Weil R. Percutaneous biliary drainage in diffuse Caroli's disease. Am J Radiol 1986;147:159-60.

48. Gobien RP, Stanley JH, Soucek CD, Anderson MC, Vujic I, Gobien BS. Routine preoperative biliary drainage: Effect on management of obstructive jaundice. Radiology 1984:152:353-6.

49. Hatfield ARW, Terblanche J, Fataar S et al. Preoperative external biliary drainage in obstructive jaundice: $A$ prospective controlled clinical trial. Lancet 1982; ii:896-9.

50. Vogelzang RL. Pain control for percutaneous biliary procedures. Semin Intervent Radiol 1988;5:207-12.

51. Lieberman RP, Nance PN, Cuka DJ Anterior approach to celiac plexus block during interventional proce. dures. Radiology 1988;167:562-4.

52. Lieberman RP, Lieberman SL, Cuka DJ, Lund GB. Celiac plexus and 
splanchnic nerve block: A review. Semin Intervent Radiol 1988;5:213-22.

53. Rosenblatt M, Robalino J, Bergman A, Shevde K. Pleural block: Technique for regional anesthesia during percutaneous hepatobiliary drainage. Radiology 1989;172:279-80.

54. van Sonnenberg E, D'Agostino HB, Casola G, Varney RR, Ainge GD. Interventional radiology in the gallbladder: Diagnosis, drainage, dissolution and management of stones. Radiology 1990;174:1-6.

55. Gunther RW, Schild H, Thelen M. Percutaneous transhepatic biliary drainage: Experience with 311 procedures. Cardiovasc Intervent Radiol 1988;11:65-71

56. Nakayama T, Ikeda A, Okuda K. Percutaneous transhepatic drainage of the biliary tract. Technique and results in 104 cases. Gastroenterology 1978;74:554-9.

57. Makuuchi M, Bandai Y, Ito T, et al Ultrasonically guided percutaneous transhepatic bile drainage. Radiology 1980;136:165-9.

58. Cohan RH, Illescas FF, Saeed M, et al. Infectious complications of percutaneous biliary drainage. Invest Radiol 1986;21:705-9

59. Caridi IG, Hawkins IF, Hawkins MC. Single-step placement of a self-retaining accordion catheter. Am J Radiol 1984;143:337-40

60. Mueller PR, Ferrucci JT, van Sonnenberg E, et al. Obstruction of the left hepatic duct: Diagnosis and treatment by selective fine needle cholangiography and percutaneous biliary drainage. Radiology 1982;145:297-302.

61. Jaques PF, Mandell VS, Delany DJ, Nath PH. Percutaneous transhepatic biliary drainage: Advantages of the leftlobe subxyphoid approach. Radiology 1982:145:534-6.

62. Casteneda-Zuniga W, Tadauarthy SM, Laerum F, Amplatz K. Anterior approach for biliary duct drainage. Radiology 1981;139:746-7.

63. May GR. Percutaneous transhepatic cholangiography and interventional biliary procedures. Refresher course. Radioligical Society of North America, Chicago, 1982.

64. Druy EM, Melville GE. Obstructed hepatic duct bifurcation: Decompression via single percutaneous tract. Am J Radiol 1984;143:73-6.

65. Uflacker R, Mourao GS, Piske RL Lima S. Percutaneous transhepatic biliary drainage: Alternatives in left hepatic duct obstruction. Gastrointest Radiol 1989;14:137-42.

66. Sarrafizadeh MS, Philip PK, Goldman ML. Percutaneous transhepatic T-tube placement for antegrade biliary drainage. Radiology 1980;137:545-6.

67. Burke DR, McLean GK. Obstructions of the hepatic duct confluence: Internal drainage of biliary lesions with a single catheter. Radiology 1989;172:1035-8.
68. McLean GK, Ring EJ, Freiman DB. Therapeutic alternatives in the treatment of intrahepatic biliary obstruction. Radiology 1982;145:289-95.

69. Hoevels J, Nilsson U. Intrahepatic vascular lesions following nonsurgical percutaneous transhepatic bile duct intubation. Gastrointest Radiol 1980;50:127-35.

70. Hamlin JA, Friedman M, Stein MG, Bray JF. Percutaneous biliary drainage: Complications of 118 consecutive catheterizations. Radiology 1986;158:199-202

71. Mitchell SE, Shuman LS, Kaufman SL, et al. Biliary catheter drainage complicated by hemobilia: Treatment by balloon embolotherapy. Radiology 1985; 157:645-52

72. Carrasco CH, Zornoza J, Bechtel W]. Malignant biliary obstruction: Complications of percutaneous biliary drainage. Radiology 1984;152:343-6.

73. Audisio RA, Bozzeti F, Severini F, et al. The occurrence of cholangit is after percutaneous biliary drainage: Evaluation of some risk factors. Surgery 1988;103:507-12

74. Gordon RL, Oleaga JA, Ring EJ, Freiman DB, Funaro AH. Replacing the "fallen out" catheter. Radiology $1980 ; 134: 537$

75. Cope C. Endoscopic replacement of drain catheters. Am J Radiol 1981;137:626-7.

76. Neff CC, Mueller PR, Ferrucci JT, et al. Serious complications following transgression of the pleural space in drainage procedures. Radiology 1984;152:335-41

77. Anschuetz SL, Vogelzang RL. Malignant pleural effusion: A complication of transhepatic biliary drainage. Am J Radiol 1986;146:1165-6.

78. Oleaga JA, Ring EJ, Freiman DB, McLean GK, Rosen RJ. Extension of neoplasm along the tract of a transhepatic tube. Am J Radiol 1980;135:841-2.

79. Miller GA, Heaston DK, Moore AV, Mills SR, Dunnick NR. Peritoneal seeding of cholangiocarcinoma in patients with percutaneous biliary drainage. Am J Radiol 1983;141:561-2.

80. Severini A, Bellomi M, Cozzi G, Bellegotti L, Lattuada A. Rib erosion: Late complication of long-standing biliary drainage catheters. Radiology 1984;150:666.

81. Lieberman RP, Sleder PR. Pain control after percutaneous biliary drainage: Local infiltration with bupivacaine and epinephrine. Am J Radiol 1986;146:595-6

82. Gould J, Train JS, Dan SJ, Mitty HA. Duodenal perforation as a delayed complication of placement of a biliary endoprosthesis. Radiology $1988 ; 167: 467-9$

83. Teplick SK, Haskin PH. Solution to a knotty biliary drainage problem. $\mathrm{Br}]$ Radiol 1986;59:511-2

84. Lillemoe KD, Pitt HA, Kaufman SL,
Cameron JL. Acute cholecystitis occurring as a complication of percutaneous transhepatic drainage. Surg Gynecol Obstet 1989;168:348-52.

85. Yee ACN, Ho CS. Complications of percutaneous biliary drainage: Benign vs malignant diseases. Am J Radiol 1987;148:1207-9.

86. Huibregtse K. Endobiliary prosthesis for malignant disease. Presented at the Second International Course on Therapeutic Endoscopy, Toronto, October 1985.

87. Soehendra N. Endobiliary prostheses: The Hamburg experience. Presented at the First International Course on Therapeutic Endoscopy, Toronto, October 1983

88. Lammer J, Neumayer K. Biliary drainage endoprosthesis: Experience with 201 placements. Radiology 1986:159:625-9.

89. Iaccarino V, Niola R, Porta E. Silicone biliary stents. Am J Radiol 1987;148:741-3.

90. Speer AG, Cotton PB, Russell R, et al. Randomised trial of endoscopic versus percutaneous stent insertion in malignant obstructive jaundice. Lancet $1987 ;$ ii:57-62

91. Mendez G, Russell E, LePage JR, Guerra J], Posniak RA, Trefles M. Abandonment of endoprosthetic drainage technique in malignant biliary obstruction. Am J Radiol 1984;143:617-22.

92. McLean GK, Burke DR. Role of endoprostheses in the management of malignant biliary obstruction. Radiology 1989;170:961-7.

93. Karlan RK, Ring EJ, Pogany AC, Jeffrey RB. Biliary endoprostheses. Insertion using a combined peroral-transhepatic method. Radiology 1984;150:828-30.

94. Hall RI, Denyer ME, Chapman AH. Palliation of obstructive jaundice with a biliary endoprosthesis. Comparison of insertion by the percutaneous-transhepatic and the combined percutaneous-endoscopic routes. Clin Radiol 1989;40:186-9.

95. Brown AS, Mueller PR, Ferrucci JT. Transhepatic removal of obstructed Carey-Coons biliary endoprosthesis. Radiology 1986;159:555-6.

96. Coons HG. Self-expanding stainless steel biliary stents. Radiology 1989;170:979-83.

97. Gillams A, Dick R, Dooley JS, Wallsten H, El-Din A. Self-expandable stainless steel braided endoprosthesis for biliary strictures. Radiology 1990; 174:137-40.

98. Alvarado R, Palmaz JC, Garcia OJ, Tio FO, Rees CR. Evaluation of polymer coated balloon-expandable stents in bile ducts. Radiology 1989;170:975-8.

99. Irving JO, Adam A, Dick R, Dondelinger RF, Lunderquist A, Roche A. Gianturco expandable metallic biliary stents: Results of a European clinical trial. Radiology 1989;172:321-6. 


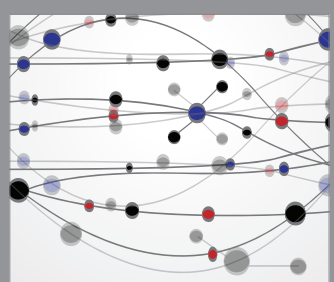

The Scientific World Journal
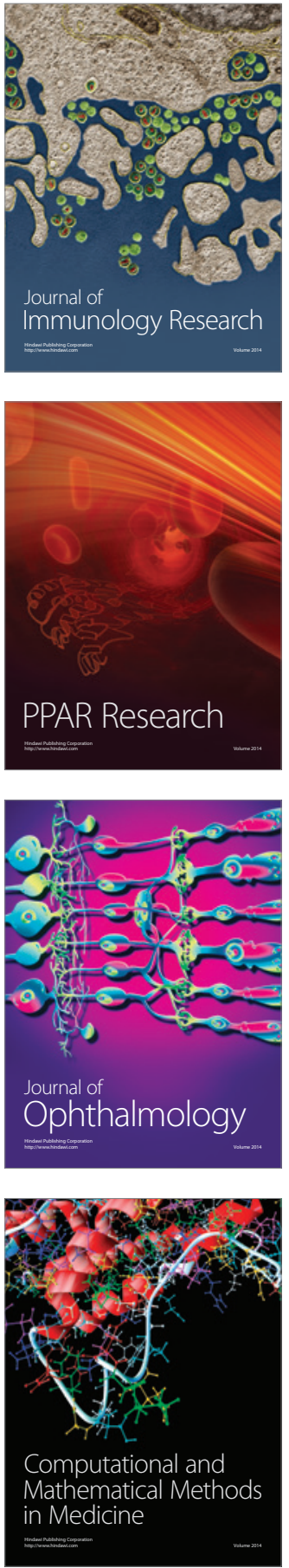

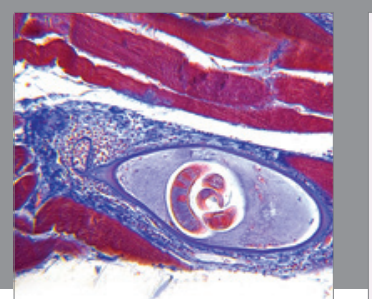

Gastroenterology Research and Practice

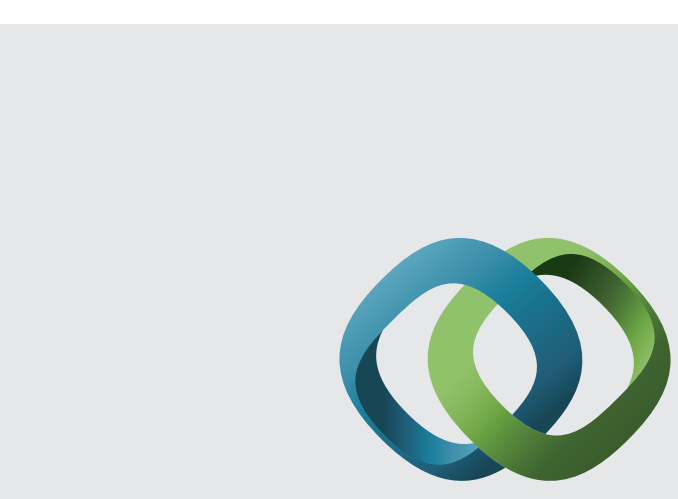

\section{Hindawi}

Submit your manuscripts at

http://www.hindawi.com
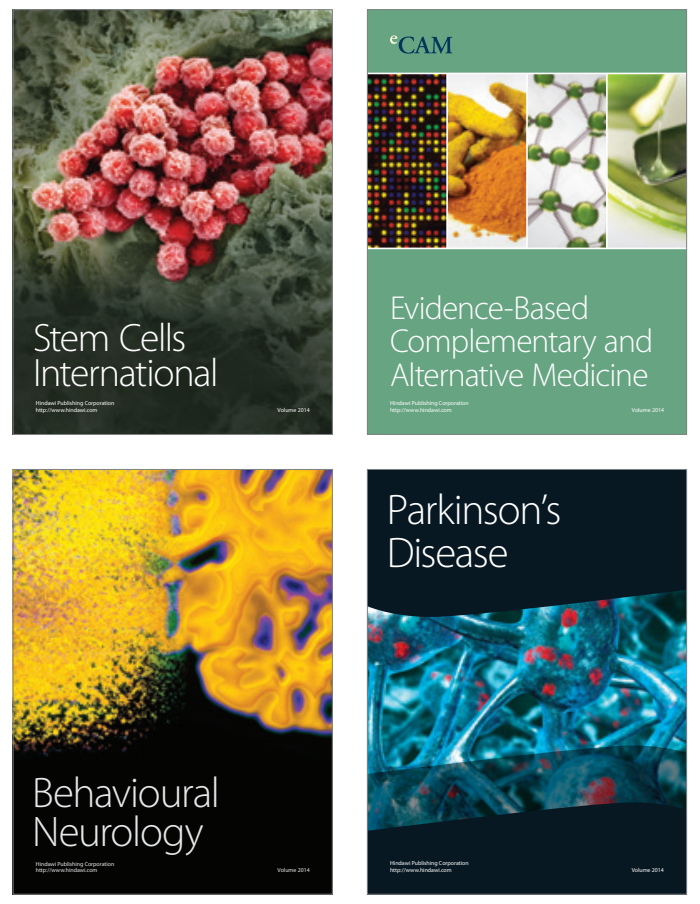
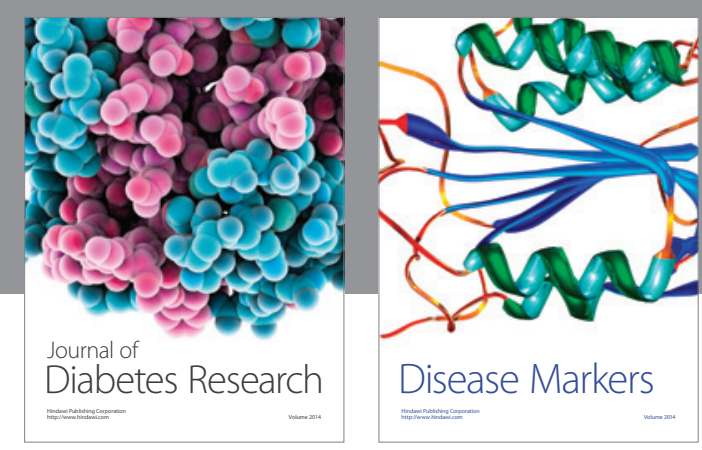

Disease Markers
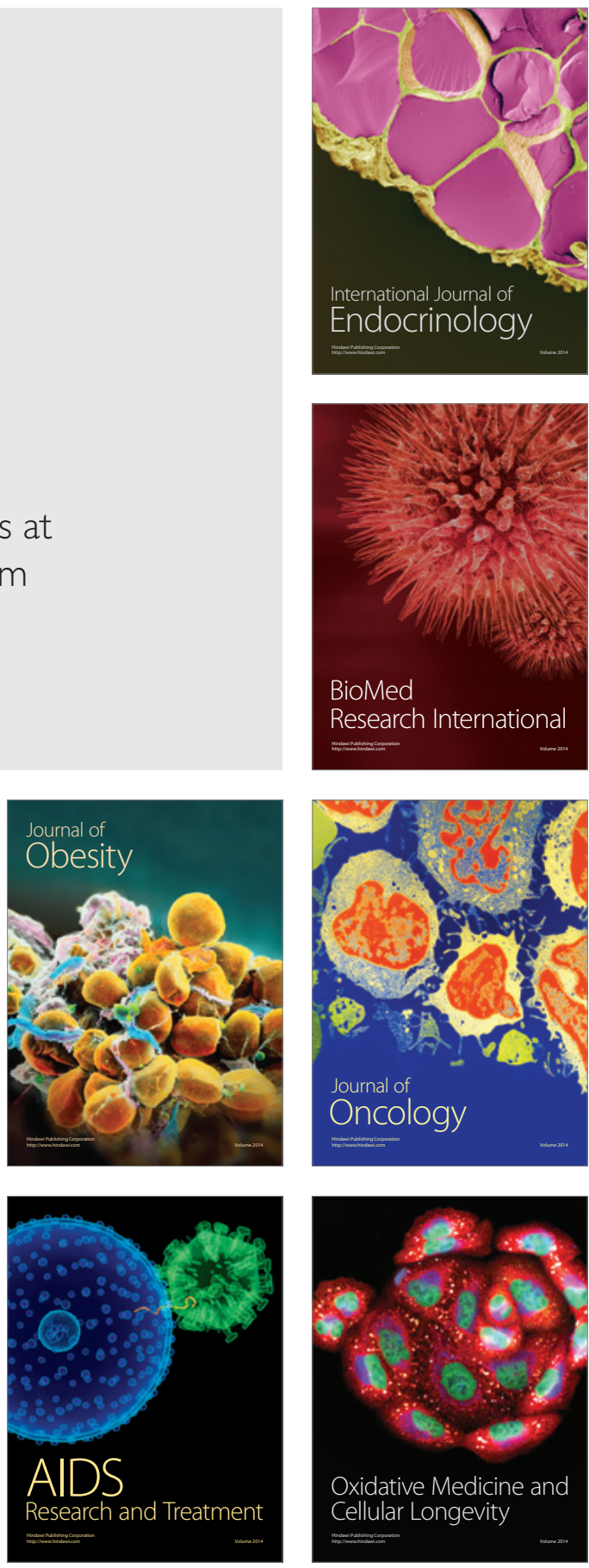